\title{
ELEVATION AND SUBSIDENCE IN CENTRAL AMERICA.
}

Srr,--Allow me to point out that Mr. W. Upham's letter in the February Number of this Magazine is not an answer to my article in that for December, 1890 ; because he completely ignores the point of my communication and re-asserts views which I did not question.

In his original article of November, 1890, Mr. Upham cited the Gulf of Mexico as having partaken in the high continental elevation and in the subsequent subsidence to an extent of 3000 feet. In December I quoted facts to prove that on the south side of the Gulf of Mexico there has been a recent upward movement of probably $2000 \mathrm{ft}$. Hence if the Mississippi subsidence was contemporaneous with the Cuban elevation, there must have been a differential movement of 5000 feet within a comparatively small area.

I do not say the difficulty is unsurmountable; the axis of the one oscillation may not have been located along the same parallel as the axis of the other oscillation, or if $\mathrm{Mr}$. Upham likes he can postulate a great east and west fault through the Gulf of Mexico, with a downthrow on the north of about 5000 feet. The point, however, does require notice, and it is not noticed at all in the letter which purports to be a reply. I will therefore put the difficulty more fully. During Pliocene and Pleistocene time there was in North America a great elevation followed by a great subsidence; and in Central America a subsiclence followed by great elevation. If these movements were correlative, should we not expect to find a zone where there was no movement at all? Would not the greatest vertical displacement be found in Canada or the Northern States, and the least in the Southern States, and would not the evidences of subsidence die away southward, and then be replaced by evidences of upheaval? Instead of this, we find the movements almost at a maximum in those parts of the two areas which are nearest to one another. Can Mr. Upham refer to any evidence about alteration of levels along the west coast of the Gulf of Mexico?

In a paper just read before the Geological Society, I have adduced evidence of the recent uprise of the Caribbean and Panamic region, and have advocated the view that the Gulf Stream passed into the Pacific while the Glacial Period prevailed in the North Atlantic. I am therefore strongly disposed to agree with the general views put forward by Mr. Upham as to the geographical conditions that prevailed during that period; but in generalizing about the movements which have affected such vast areas, we cannot be too careful about the accuracy of the data on which the inferences are based, and nothing is gained by ignoring difficulties.

It was because I thought that this difficulty might not have occurred to Mr. Upham that I put it before him; but I shall be very pleased to see it answered in a manner that will strengthen Mr. Upham's theory of correlative movements, and I hope Dr. Spencer, who wrote much more cautiously than Mr. Upham, may shortly have something to say about the date of the great depression.

Teignmoutr, February $7 t h$.

A. J. Jukes-Browne. 